\title{
Loss of runt-related transcription factor 3 expression leads hepatocellular carcinoma cells to escape apoptosis
}

\author{
Yutaka Nakanishi', Hidenori Shiraha ${ }^{1 *}$, Shin-ichi Nishina', Shigetomi Tanaka', Minoru Matsubara', \\ Shigeru Horiguchi', Masaya Iwamuro', Nobuyuki Takaoka', Masayuki Uemura', Kenji Kuwaki, Hiroaki Hagihara, \\ Junichi Toshimori, Hideki Ohnishi ${ }^{1}$, Akinobu Takaki ${ }^{1}$, Shinichiro Nakamura' ${ }^{1}$, Yoshiyuki Kobayashi ${ }^{1}$, \\ Kazuhiro Nouso ${ }^{1,2}$, Takahito Yagi ${ }^{3}$, Kazuhide Yamamoto ${ }^{1}$
}

\begin{abstract}
Background: Runt-related transcription factor 3 (RUNX3) is known as a tumor suppressor gene for gastric cancer and other cancers, this gene may be involved in the development of hepatocellular carcinoma (HCC).

Methods: RUNX3 expression was analyzed by immunoblot and immunohistochemistry in HCC cells and tissues, respectively. Hep3B cells, lacking endogenous RUNX3, were introduced with RUNX3 constructs. Cell proliferation was measured using the MTT assay and apoptosis was evaluated using DAPI staining. Apoptosis signaling was assessed by immunoblot analysis.
\end{abstract}

Results: RUNX3 protein expression was frequently inactivated in the HCC cell lines (91\%) and tissues (90\%). RUNX3 expression inhibited $90 \pm 8 \%$ of cell growth at $72 \mathrm{~h}$ in serum starved Hep3B cells. Forty-eight hour serum starvation-induced apoptosis and the percentage of apoptotic cells reached $31 \pm 4 \%$ and $4 \pm 1 \%$ in RUNX3expressing Hep3B and control cells, respectively. Apoptotic activity was increased by Bim expression and caspase-3 and caspase-9 activation.

Conclusion: RUNX3 expression enhanced serum starvation-induced apoptosis in HCC cell lines. RUNX3 is deleted or weakly expressed in HCC, which leads to tumorigenesis by escaping apoptosis.

\section{Background}

Hepatocellular carcinoma $(\mathrm{HCC})^{1}$ is the sixth most common cancer and responsible for more than half a million deaths worldwide each year [1-3]. Although most $\mathrm{HCC}$ cases occur in East Asia and Middle and West Africa, its incidence in some developed countries is increasing [1,4]. In most cases, HCC is fatal because of an incomplete understanding of the pathogenic mechanisms and inadequacies of early detection $[1,5]$.

The activation of proto-oncogenes plays a major role in the development of HCC [1,6-8], and a number of tumor suppressor genes may be associated with the

\footnotetext{
* Correspondence: hshiraha@md.okayama-u.ac.jp

'Department of Gastroenterology and Hepatology, Okayama University Graduate School of Medicine and Dentistry, 2-5-1 Shikata-cho, Okayama 7008558, Japan

Full list of author information is available at the end of the article
}

development and progression of HCC [1,9-12]. Although several cancer-related genes are altered in $\mathrm{HCC}$, the frequency of alterations for each individual gene is relatively low. In $\mathrm{HCC}$, the alteration of tumor suppressor genes seems to be more important than that of oncogenes. Established genetic events include the loss of an allele, mutation, or promoter methylation [13-16]. A higher loss of heterozygosity ( $\mathrm{LOH}$ ) frequency was detected at several loci on chromosomes 8p23, 4q22-24, $4 \mathrm{q} 35,17 \mathrm{p} 13,16 \mathrm{q} 23-24,6 \mathrm{q} 27,1 \mathrm{p} 36$, and 9p12-14, suggesting the presence of important tumor suppressor genes at these loci [17]. However, there is little understanding of the several key pathways and the genes involved in these pathways.

Runt-related transcription factor 3 (RUNX3), located on chromosome $1 \mathrm{p} 36$, is correlated with tumorigenesis and gastric cancer progression $[18,19]$. RUNX3 acts as

\section{() Biomed Central}


an apoptotic factor, downstream of transforming growth factor- $\beta$ (TGF- $\beta$ ), and as a cell differentiation mediator in intestinal metaplasia of gastric mucosa [19-21]. In gastric cancer cell lines, RUNX3-induced apoptosis depends on Bim expression [22]. RUNX3 protein expression is decreased about $45-60 \%$ in human gastric cancer [21] and has been detected in some human malignancies such as those of the colon, lung, pancreas, and bile duct [23-26]. RUNX3 gene expression decreased in $30-80 \%$ of HCCs due to $\mathrm{LOH}$ and methylation of its promoter $[27,28]$. The loss or decrease of RUNX3 expression in HCC tissue has been recently reported [29], but the precise function of RUNX3 in HCC needs to be elucidated.

\section{Methods}

\section{Cell lines and cell culture}

The HCC cell lines HepG2, Hep3B, PLC/PRF/5 (PLC), and SK-Hep1 were obtained from the American Type Culture Collection (Manassas, VA), and the Huh1, Huh7, JHH1, JHH2, JHH4, HLE, and HLF cell lines were obtained from the Health Science Research Resources Bank (Osaka, Japan). Normal human hepatocytes were obtained from Sanko Junyaku Co. Ltd. (Tokyo, Japan). JHH2 and normal human hepatocytes were cultured in William's medium E (Invitrogen, Carlsbad, CA). Other cell lines were maintained in Dulbecco's modified Eagle's medium (Invitrogen). Media were supplemented with $10 \%$ heat-inactivated fetal bovine serum (FBS) (Sigma, St. Louis, MO), 1\% nonessential amino acids (Sigma), 1\% sodium pyruvate (Sigma), and $1 \%$ penicillin/streptomycin solution (Sigma). Cells were cultured at $37^{\circ} \mathrm{C}$ in a humidified atmosphere of $5 \% \mathrm{CO}_{2}$ and 95\% air. Quiescence was carried out under restricted serum conditions with $0.1 \%$ dialyzed FBS for the indicated time periods.

\section{RNA preparation and reverse transcriptase-polymerase chain reaction}

Total RNA was isolated from cells using Trizol $^{\mathrm{TM}}$ reagent (Invitrogen). Reverse transcription was performed using random primers and ReverTra Ace ${ }^{\mathrm{Tm}}$ (Toyobo, Osaka, Japan) reverse transcriptase (RT). Ps-CA and Ps-CB, previously published primer set for RUNX3, were utilized [21]. For each polymerase chain reaction (PCR), $20 \mu \mathrm{l}$ (total volume) of reaction mixture contained $0.1 \mu \mathrm{g}$ template DNA, 4 pmol each of the forward and reverse primers, $2 \mu$ deoxynucleoside triphosphates (200 mM each), $1 \mathrm{U}$ pfu Turbo ${ }^{\mathrm{Tm}}$ DNA polymerase (Stratagene, La Jolla, $\mathrm{CA}$ ), and $2 \mu \mathrm{l}$ of $10 \times$ pfu reaction buffer. PCR amplification was conducted on an $\mathrm{iCycler}^{\mathrm{TM}}$ (Bio-Rad, Hercules, $\mathrm{CA}$ ) with the following cycle conditions: cycle $1,95^{\circ} \mathrm{C}$ for $2 \mathrm{~min}$; cycles $2-30,95^{\circ} \mathrm{C}$ for $30 \mathrm{~s}, 58^{\circ} \mathrm{C}$ for $30 \mathrm{~s}$, and $72^{\circ} \mathrm{C}$ for $120 \mathrm{~s}$, with a final elongation step of $72^{\circ} \mathrm{C}$ for $10 \mathrm{~min}$.

\section{Immunoblot analysis}

Cells were plated onto 6-well tissue culture plastic dishes and grown to confluence. After cultivating the cells under the indicated conditions, they were washed twice with cold phosphate-buffered saline (PBS) and lysed in $150 \mu \mathrm{l}$ of sample buffer (100 mM Tris-HCl, pH 6.8, 10\% glycerol, 4\% sodium dodecyl sulfate [SDS], 1\% bromophenol blue, 10\% $\beta$-mercaptoethanol). The samples were resolved by SDS-polyacrylamide gel electrophoresis (PAGE) and transferred to Immobilon- $\mathrm{P}^{\mathrm{Ts}}$ polyvinylidene difluoride membranes (Millipore Corporation, Bedford, MA), which were blocked using Tris-buffered saline with Tween-20 (TBS-T) (Sigma) containing 5\% bovine serum albumin for $1 \mathrm{~h}$. The membranes were incubated with antibodies against RUNX3 (R3-G54; Abcam, Cambridge, MA), poly-histidine (His) (Roche Diagnostics, Basel, Switzerland), Bax, Bcl-2, Bim, cleaved caspase-3 and -9 (Cell Signaling Technology, Beverley, MA), and $\beta$-actin (Sigma) overnight at $4^{\circ} \mathrm{C}$. We washed the membranes three times with TBS-T and probed with horseradish peroxidase-conjugated secondary antibodies before developing them using an ECL Western blotting detection system (Amersham Biosciences, Piscataway, NJ) by enhanced chemiluminescence.

\section{HCC tissue and immunohistochemistry}

Thirty-one patients including 24 men with age ranging from 18 to 71 years (average age, 58 years) and 7 women with age ranging from 59 to 67 years (average age, 63 years) at the time of hepatic resection were included in this study. HCC tissues along with adjacent liver tissues were used for analysis. As per the institutional guidelines, we obtained informed consent from all donors of liver tissue samples, and the study was approved by the Research Ethics Committee of Okayama University.

Immunohistochemistry was performed on formalinfixed paraffin sections that were dewaxed and dehydrated. After rehydration, endogenous peroxidase activity was blocked for $30 \mathrm{~min}$ in a methanol solution containing $0.3 \%$ hydrogen peroxide. After antigen retrieval in citrate buffer, the sections were blocked overnight at $4{ }^{\circ} \mathrm{C}$. The sections were probed with rabbit polyclonal antibody (ab49117; Abcam) followed by biotinylated anti-rabbit secondary antibody (Dako Japan, Tokyo, Japan). The signal was amplified by avidin-biotin complex formation and developed with diaminobenzidine followed by counterstaining with hematoxylin, after which the sections were dehydrated in alcohol and xylene, and mounted for observation. The sections were scored on a four-tier scale; 0 , negative; 1 , weak signal; 2 , intermediate signal; and 3, strong signal [30]. All sections were scored independently by two observers (Y. K. and K. N.) without prior knowledge. All discrepancies in scoring were reviewed and a consensus was reached. 


\section{RUNX3 cloning and transfection}

We obtained human RUNX3 cDNA by PCR-based cloning from normal human hepatocytes (Sanko Junyaku). Briefly, cDNA was amplified by PCR using sense (5'TATGCGTATTCCCGTAGA) and antisense (5'CTCGAGGCGGCCGCTCAATGGTGATGGTGAT GATGACCGGTACGGTAGGGCCGCCACAC; including the six-His tag) oligonucleotide primers with $\mathrm{Pfu}$ Turbo $^{\mathrm{TM}}$ Hotstart DNA polymerase (Stratagene) and cloned into the PCR II TA cloning vector (Invitrogen). The size of the PCR product was $\sim 1.2 \mathrm{~kb}$. After confirmation by sequencing, RUNX3 cDNA was subcloned into pCEP4 (Stratagene), downstream from a cytomegalovirus promoter. The poly-His tag was replaced with green fluorescent protein (GFP) cDNA from pEGFP-C1 (Clontech, Palo Alto, CA). The human RUNX3 and/or chloramphenicol acetyltransferase (CAT) (control) constructs were transfected into Hep3B cells using FuGENE ${ }^{\mathrm{Tm}} 6$ transfection reagent (Roche), as per the manufacturer's instruction. Cells were selected in complete medium containing $250 \mu \mathrm{g} / \mathrm{ml}$ of hygromycin (Roche). Polyclonal lines consisting of more than 20 colonies were established. At least two independent stably transfected lines were established for each construct.

Transient RUNX3 expression was also conducted using FuGENE ${ }^{\mathrm{TM}} 6$ in Hep3B, Huh7, HLE, and HLF cells. After transfection, the cells were cultured under serum starved condition for the indicated periods, if needed, and utilized for the following experiments.

\section{MTT assay}

Cell proliferative activity was assessed with the 3-(4, 5dimethylthiazol-2-yl)-2, 5-diphenyl tetrazolium bromide (MTT) assay. Briefly, cells were seeded at 2,000 cells/ well in 96-well tissue culture plastic dishes and quiesced for $6 \mathrm{~h}$ with $0.1 \%$ dialyzed FBS. After 24-120 h of quiescence, the cells were cultured for the indicated periods with or without $10 \%$ FBS. At the end of the treatment, $10 \mu \mathrm{l}$ of MTT (5 mg/ml in PBS) was added to each well, and the wells were incubated for an additional $2 \mathrm{~h}$ at $37^{\circ} \mathrm{C}$. The purple-blue MTT formazan precipitate was dissolved in $200 \mu \mathrm{l}$ of dimethyl sulfoxide (Sigma). The activity of the mitochondria, reflecting cellular growth and viability, was evaluated by measuring the optical density at $570 \mathrm{~nm}$ with a microplate reader (Bio-Rad).

\section{DAPI staining}

Cells were plated at $50 \%$ confluence on glass chamber slides (Labtek II, Nalgen Nunc, Roskide, Denmark) and quiesced for $6 \mathrm{~h}$ with a media containing $0.1 \%$ dialyzed FBS. Then, they were treated with $10 \%$ FBS, $100 \mu \mathrm{M}$ caspase inhibitor (caspase inhibitor IV, Calbiochem, Gibbstown, NJ), $1 \mathrm{nM}$ transforming growth factor- $\alpha$ (TGF- $\alpha$ ) (Peprotech Inc. Rocky Hill, NJ), 1 nM epidermal growth factor (EGF) (Peprotech), and/or 5 $\mathrm{ng} / \mathrm{ml}$ platelet derived growth factor (PDGF)-BB (Peprotech). Chromosomal DNA was stained with 4', 6-diamidine-2'-phenylindole dihydrochloride (DAPI) (Dojindo, Kumamoto, Japan) according to the manufacturer's instructions. Briefly, treated cells were washed with PBS and stained with DAPI working solution $(1 \mu \mathrm{g} / \mathrm{ml}$ in PBS) for $2 \mathrm{~min}$. The percentage of cells with condensed chromatin and/or fragmented nuclei was established in 300-500 DAPI-stained cells examined under a fluorescence microscope (IX-70, Olympus, Tokyo, Japan).

\section{Flow cytometry analysis}

Annexin $\mathrm{V}$ and propidium iodide (PI) staining was performed using an annexin $\mathrm{V}$-fluorescein isothiocyanate (FITC) Apoptosis Detection kit (Medical \& Biological Laboratories Co., Ltd., Nagoya, Japan) to measure apoptosis. Cells were cultured in $10-\mathrm{cm}$ tissue culture plates and quiesced for $6 \mathrm{~h}$ with a media containing $0.1 \%$ dialyzed FBS. Cells were cultured in medium with or without $10 \%$ FBS for $24 \mathrm{~h}$. Then, they were washed twice with PBS, collected, and re-suspended in $85 \mu \mathrm{l}$ of $1 \times$ annexin V-FITC binding buffer. Five microliters of annexin V-FITC conjugate and $10 \mathrm{ml}$ of PI buffer were added, and the cells were incubated at room temperature for $15 \mathrm{~min}$ in the dark. After adding $400 \mu \mathrm{l}$ of $1 \times$ annexin V-FITC binding buffer, cells were analyzed using a flow cytometer (FACS Calibur; Becton Dickinson, Franklin Lakes, NJ).

\section{Gene silencing of Bim with small interfering RNA}

RUNX3-expressing Hep3B cells were transfected with either scrambled negative control small interfering RNA (siRNA) or Bim siRNA (Applied Biosystems, Foster City, CA). siRNAs were transfected into cells using RNAiFect $^{\mathrm{m}}$ transfection reagent (Qiagen, Hilden, Germany). Cells were incubated with scrambled negative control siRNA or Bim siRNA for $24 \mathrm{~h}$ before $48 \mathrm{~h}$ of serum starvation. The MTT assay and DAPI staining for detecting apoptosis were performed as described above.

\section{Results}

\section{Loss of RUNX3 expression in HCC cell lines and human} HCC tissues

A decreased level or absence of RUNX3 mRNA expression was observed in 10 of $11 \mathrm{HCC}$ cell lines (Figure 1A). RUNX3 mRNA was undetectable in eight cell lines (HepG2, Hep3B, Huh1, Huh7, JHH1, JHH2, JHH4, and HLE). In HLF and SK-Hep1 cells, RUNX3 mRNA was significantly underexpressed (Figure 1A). Normal human hepatocytes expressed RUNX3 mRNA. Sequence analysis was performed in HLF, PLC, and SK-Hep1 cells, and no mutation was detected. In accordance with the mRNA analysis, RUNX3 protein expression was 


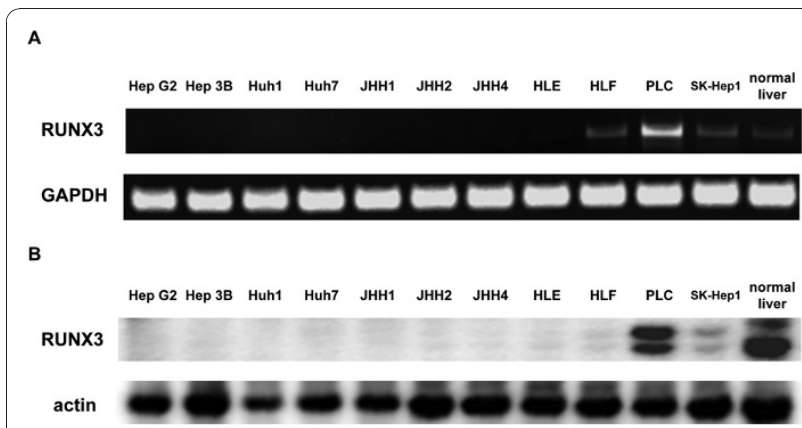

Figure 1 RUNX3 mRNA (A) and protein (B) expression in HCC cell lines. (A) RUNX3 and GAPDH mRNA expression levels were determined by RT-PCR. Shown here are representative gels from three independent experiments. (B) RUNX3 and $\alpha$-actin protein expression was analyzed by immunoblot using the anti-RUNX3 antibody. Shown here are representative blots from more than three independent experiments.

undetectable in the HepG2, Hep3B, JHH1, JHH2, JHH4, HLE, and HLF cell lines, while the RUNX3 protein was expressed in HLF, PLC, and SK-Hep1 cells (Figure 1B). The RUNX3 protein was significantly underexpressed in HLF and SK-Hep1 cells.

RUNX3 protein expression in human HCC tissue was compared to that in the corresponding tumor-free resection margins using immunohistochemical analysis (Figure 2$)$. Twenty eight ( $90 \%)$ of these pairs showed a negative or weak signal for RUNX3 expression in HCC tissue, but showed RUNX3 protein expression in tumorfree resection margins (Table 1 ). In the remaining three pairs, a weak RUNX3 expression signal was detected in the tumor-free resection margins; thus, no negative RUNX3 signal was detected in the tumor-free resection margins.

\section{Ectopic RUNX3 protein expression in Hep3B cells}

To assess whether RUNX3 protein expression affected cell survival in the HCC cell lines, a RUNX3 construct was introduced into RUNX3-negative Hep3B cells (Figure $3 \mathrm{~A})$. Overall, the clones were expressed at similar

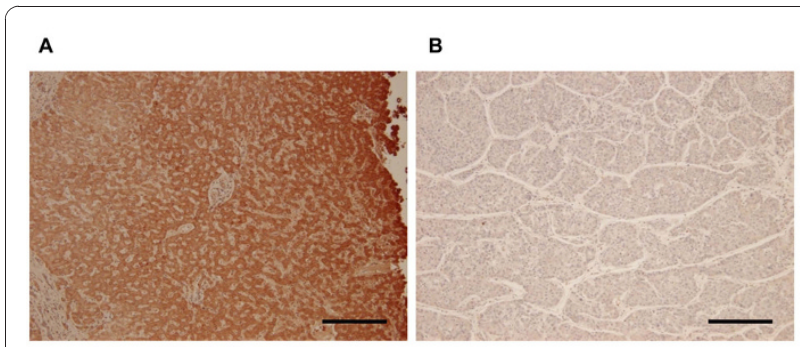

Figure 2 Immunohistochemical staining of RUNX3 in human liver tissues. (A) nontumor liver tissue with a protein score of 3 (B) HCC tissue with a protein score of 0 . Bar $=100 \mu \mathrm{m}$.
Table 1 RUNX3 expression in HCC samples $(n=31)$ and the corresponding tumor-free resection margins

\begin{tabular}{lll}
\hline $\begin{array}{l}\text { RUNX3 protein } \\
\text { expression score }\end{array}$ & $\begin{array}{l}\text { HCC samples }(\mathbf{n} \\
\mathbf{=} \mathbf{3 1})\end{array}$ & $\begin{array}{l}\text { Tumor-free sections } \\
\mathbf{( n = 3 1 )}\end{array}$ \\
\hline 0 (negative signal) & $13(41.9 \%)$ & 0 \\
1 (weak signal) & $15(48.4 \%)$ & $3(9.7 \%)$ \\
2 (intermediate signal) & $3(9.7 \%)$ & $16(51.6 \%)$ \\
3 (strong signal) & 0 & $12(38.7 \%)$ \\
\hline
\end{tabular}

levels in all cells, as determined by immunocytochemical analysis (data not shown). RUNX3-expressing Hep3B cells grew slightly slower than normal Hep3B cells in the presence of FBS.

\section{RUNX3 expression inhibited cell growth under serum starvation}

RUNX3 has been reported to induce apoptosis in a gastric cancer cell study [21]. The MTT assay was performed to determine whether RUNX3 expression influenced cell growth. RUNX3-expressing Hep3B cells grew slightly slower than CAT-transfected Hep3B cells in the presence of FBS, whereas the growth of RUNX3expressing Hep3B cells was markedly suppressed in the absence of FBS; growth inhibition could be observed as early as $24 \mathrm{~h}$, and reached $70 \pm 12 \%$ and $90 \pm 8 \%$ at 48 and $72 \mathrm{~h}$, respectively (Figure $3 \mathrm{~B}$ ). The inhibition levels were over 4 times than those found in the condition with 10\% FBS. This effect was confirmed with GFPtagged RUNX3-expressing Hep3B cells (70 $\pm 11 \%$ growth inhibition at $72 \mathrm{~h}$ ).

\section{RUNX3 expression induced apoptosis under serum starvation}

The effect of RUNX3 expression on cell survival and the cell cycle with and without FBS was assessed to investigate whether the elicited growth suppression in RUNX3-expressing cells under serum starved conditions was due to an increase in cell death or due to cell cycle inhibition, or both. DAPI staining demonstrated that serum starvation induced apoptosis in RUNX3-expressing Hep3B cells $(31 \pm 4 \%)$ but not in CAT-transfected Hep3B cells $(4 \pm 1 \%)$ in the absence of FBS (Figure 3C). Flow cytometry analysis with annexin $\mathrm{V}$ antibody was also performed. RUNX3-expressing Hep3B cells showed a significant increase in a pre-apoptosis population (Annexin V+ PI-) after $24 \mathrm{~h}$ of serum starvation compared with CAT-transfected Hep3B cells (Figure 3D).

\section{RUNX3-induced apoptosis through the Bim-caspase pathway}

Because a RUNX3-induced apoptotic pathway has been described previously, the effect of altering RUNX3 expression was investigated. Bim protein expression was 


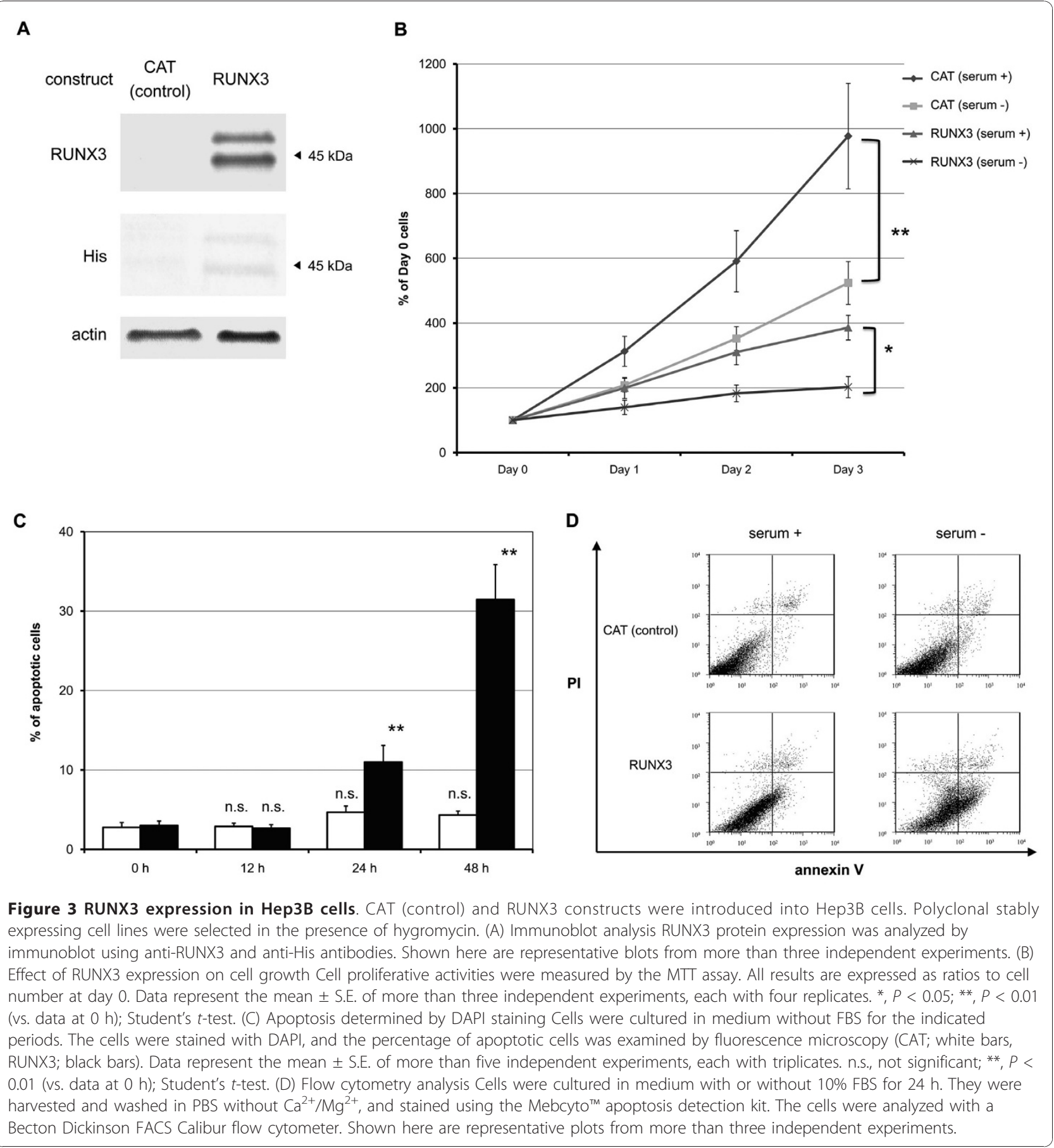

enhanced by serum starvation in RUNX3-expressing Hep3B cells but not in control cells (Figure 4A). Activated apoptosis executors, caspase- 9 and -3 , were found in serum starved RUNX3-expressing Hep3B cells. Expression of the Bim attenuators, Bax and Bcl-2, was not affected by serum starvation. These results imply that Bim plays a major role in serum starvation-induced apoptosis in RUNX3-expressing cells.
Serum starvation-induced apoptosis was abrogated by an apoptosis inhibitor (Figure 4B). Various growth factors were employed to determine whether serum starvation-induced apoptosis was caused by the absence of a growth factor-induced survival signal. As a result, TGF- $\alpha$, EGF, and PDGF abrogated serum starvationinduced apoptosis in RUNX3-expressing Hep3B cells (Figure 4B). 


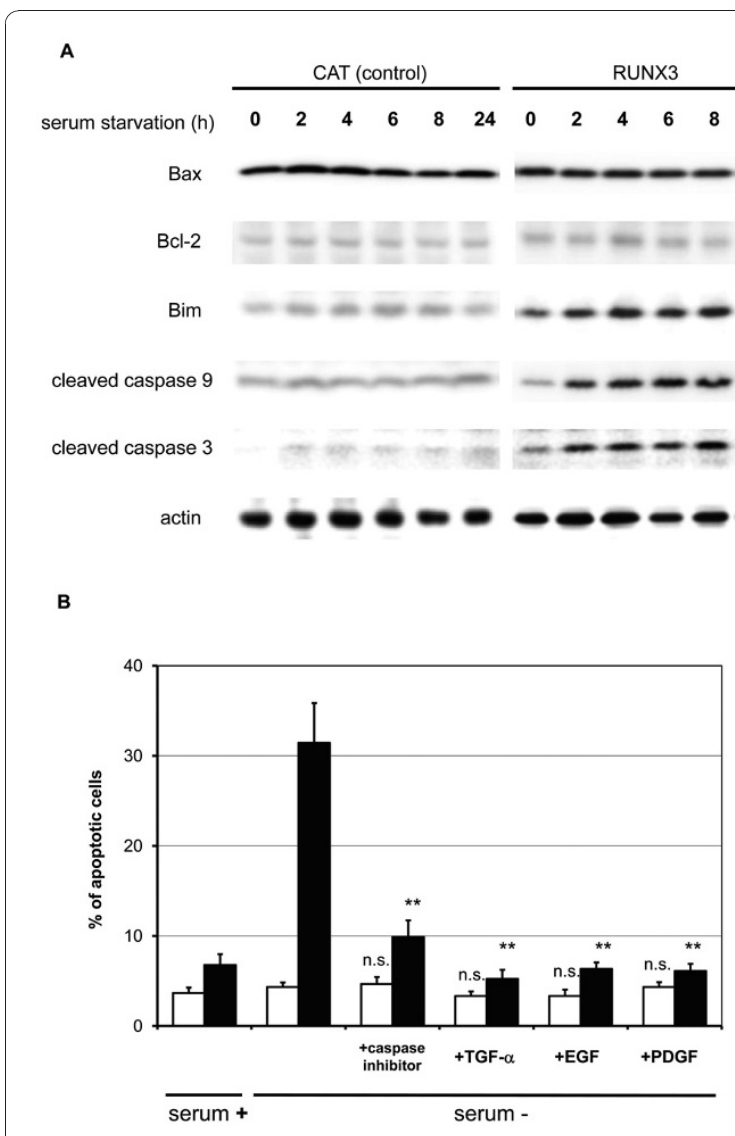

Figure 4 Effect of RUNX3 on apoptosis-related signaling molecules. (A) Immunoblot analysis Equal amounts of cell lysates were size-fractionated with 10\% SDS-PAGE and immunoblotted with antibodies against Bax, Bcl-2, Bim, cleaved caspase-9, cleaved caspase-3, and actin. Shown here are representative blots from at least three independent experiments. (B) Apoptosis determined by DAPI staining Cells were cultured in media with or without $10 \%$ FBS, caspase inhibitor, and/or TGF- $\alpha$ for $48 \mathrm{~h}$. Cells were stained with DAPI, and the percentage of apoptotic cells was determined under a fluorescent microscope (CAT; white bars, RUNX3; black bars). Data represent the mean \pm S.E. of more than five independent experiments, each with triplicates. n.S., not significant; $P>0.05 ;{ }^{*}, P<0.01$ (vs. data with no serum); Student's $t$-test.

siRNA against Bim reduced serum starvation-induced apoptosis in RUNX3-expressing Hep3B cells

siRNA against Bim was used to knockdown Bim expression in Hep3B cells (Figure 5A). The expression level of cleaved caspase-3, decreased in Bim siRNA-treated cells (Figure 5A). Bim siRNA inhibited serum starvationinduced apoptosis by $46 \pm 7 \%$ in RUNX3-expressing Hep3B cells (Figure 5B).

\section{Transient ectopic RUNX3 expression in various HCC cell lines}

RUNX3 was transiently expressed in various HCC cell lines, including Hep3B, Huh7, HLE, and HLF,

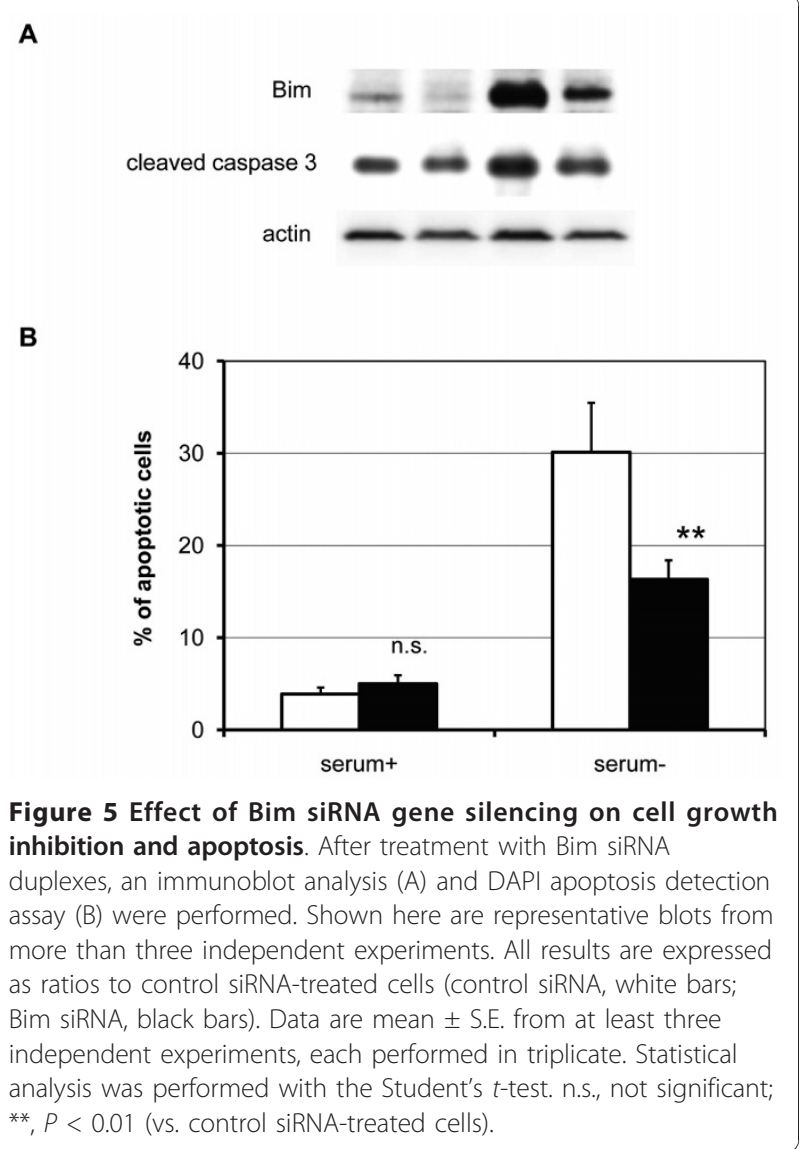

introducing a RUNX3 construct-induced RUNX3 protein expression (Figure 6A). Transient RUNX3-expressing cells also showed growth inhibition after $48 \mathrm{~h}$ of serum starvation; the inhibition was $50 \pm 10 \%, 46 \pm$ $11 \%, 60 \pm 8 \%$, and $52 \pm 9 \%$ in Hep3B, Huh7, HLE, and HLF cells, respectively. The RUNX3-expressing HCC cell lines demonstrated enhanced serum starvationinduced apoptosis; the percentage of apoptotic cells determined by DAPI staining was $21 \pm 2 \%, 25 \pm 2 \%, 19$ $\pm 1 \%$, and $20 \pm 2 \%$ in Hep3B, Huh7, HLE, and HLF cells, respectively (Figure 6B). Serum starvation-induced Bim expression and caspase- 3 cleavage were also confirmed in RUNX3-expressing Hep3B, Huh7, HLE, and HLF cells (Figure 6C).

\section{Discussion}

The results of the present study demonstrated that RUNX3 is a tumor suppressor gene for HCC. A significant down-regulation of RUNX3 was observed in a high percentage of human HCC cell lines (91\%) and tissues (90\%) (Figures 1, 2, and Table 1). RUNX3 has been described as a gastric cancer tumor suppressor [21]. In many cancer types, deletion of the RUNX3 locus and reduction of its expression by promoter hypermethylation has been 
A

$$
\frac{\text { Hep3B }}{\text { CAT RUNX3 }} \frac{\text { Huh7 }}{\text { CAT RUNX3 }} \frac{\text { HLE }}{\text { CAT RUNX3 }} \frac{\text { HLF }}{\text { CAT RUNX3 }}
$$

RUNX3

B

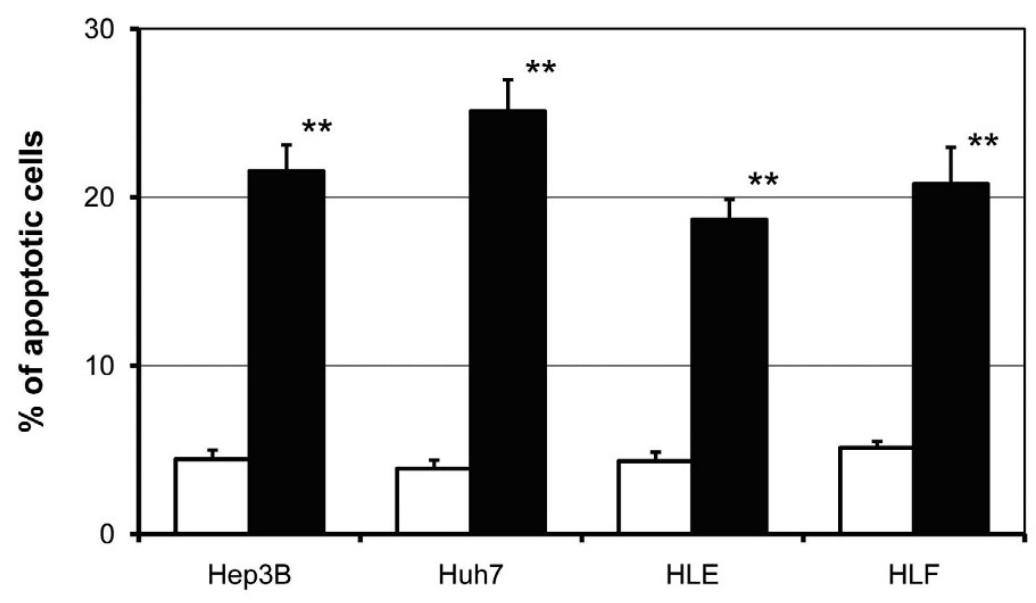

C

\begin{tabular}{|c|c|c|c|c|c|c|c|c|c|c|c|c|c|c|c|c|}
\hline & \multicolumn{4}{|c|}{ Нер3В } & \multicolumn{4}{|c|}{ Huh7 } & \multicolumn{4}{|c|}{ HLE } & \multicolumn{4}{|c|}{ HLF } \\
\hline construct & & & & & CAT & & & & & & & & & & & \\
\hline serum & + & - & + & - & + & - & + & - & + & - & + & - & + & - & + & \\
\hline
\end{tabular}

Bim

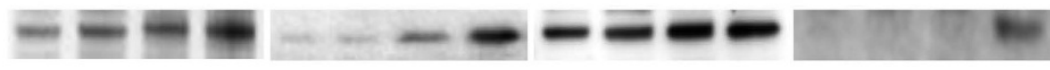

cleaved caspase 3

actin

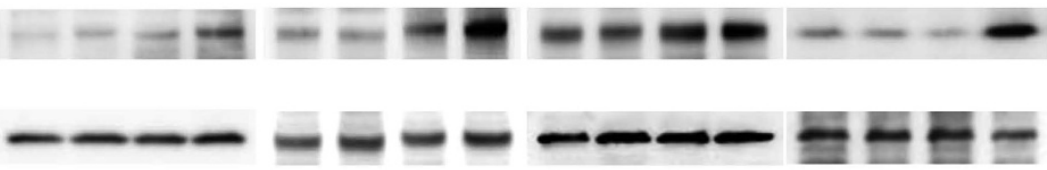

Figure 6 Effect of transient ectopic RUNX3 expression. CAT (control) and RUNX3 constructs were introduced into HCC cell lines. After a 48-h incubation period, an immunoblot analysis for RUNX3 expression (A), a DAPI apoptosis detection assay (B), and an immunoblot analysis for Bim and caspase $(C)$ were performed. Shown here are representative blots from more than three independent experiments. All results are expressed as ratios to control CAT-transfected cells (CAT; white bars, RUNX3; black bars). Data represent the mean \pm S.E. of more than five independent experiments, each with triplicates. ${ }^{*}, P<0.01$ (vs. data at 0 h); Student's $t$-test.

reported [23-26]. However, little is known about the role of RUNX3 in HCC tumor suppression. We hypothesized that loss of RUNX3 expression contributes the development of HCC by escaping apoptosis. The results of the present study provide clear evidence that RUNX3 elicits serum starvation-induced apoptosis in HCC cells by activating the Bim-caspase pathway.
Stable expression of RUNX3 protein was established in Hep3B cells (Figure 3A), and they showed apoptosis under serum starved conditions (Figure 3B). This effect was reproducible in the Hep3B, Huh7, HLE, and HLF HCC cell lines transiently expressing RUNX3. The inhibition of cell growth in transient RUNX3-expressing cells was generally lower than that in stable RUNX3- 
expressing Hep3B cells, probably due to low transfection efficiency.

Serum starvation-induced apoptosis is caused by caspase activation in ectopic RUNX3-expressing Hep3B cells (Figures $3 \mathrm{C}$ and $3 \mathrm{D}$ ). To explore the signaling molecule responsible for apoptosis, Bim protein expression was induced in serum starved RUNX3-expressing Hep3B cells (Figure 4A). This is the first report demonstrating that RUNX3 enhances Bim expression under serum starved conditions in HCC cells, which appears to be consistent with the important role of Bim in previous studies on other types of cells. Bim expression was induced by the cooperation of RUNX3 and TGF- $\beta$ in a study of gastric epithelial cells [21,31]. Bim protein also plays an important role in cell death [32]. Bim induces sequential activation of caspase-9 and -3 [32]. The potency of Bim as a cell death inducer is attenuated by Bax and Bcl-2 subfamily proteins [33]. The expression of Bax and Bcl was not affected by RUNX3 expression (Figure 4A). The expression of Bad (data not shown), a Bcl-2 antagonist known as a serum starvation-induced apoptosis initiator [34], increased with serum starvation but was not attenuated by RUNX3 expression (Figure 4A). Bim siRNA was used to evaluate whether Bim expression regulates serum starvation-induced apoptosis in RUNX3-expressing cells. As a result, Bim siRNA successfully knocked down Bim expression in RUNX3expressing Hep3B cells (Figure 5A). Knockdown of Bim expression abrogated serum starvation-induced apoptosis in RUNX3-expressing Hep3B cells (Figure 5B). Consequently, RUNX3 expression enhanced serum starvation-induced apoptosis through the Bim-caspase pathway in Hep3B cells. This effect was reproducible in the Huh7, HLE, and HLF HCC cell lines transiently expressing RUNX3 (Figure 6).

Serum starvation triggered apoptosis in RUNX3expressing HCC cells. As this leads to the question of how serum prevents apoptosis in RUNX3-expressing cells, RUNX3-expressing Hep3B cells were treated with TGF- $\alpha$, EGF, or PDGF (Figure 4C). These growth factors reduced apoptosis in RUNX3-expressing Hep3B cells by activating the PI3/Akt signaling pathway (data not shown), which is consistent with a previous report [34].

RUNX3 induces apoptosis in the presence of TGF- $\beta$ [21]. In a study of gastric epithelial cells, RUNX3 enhanced Bim expression during TGF- $\beta$-induced apoptosis [21,31]. In a study of a gastric and esophageal cancer cell lines, RUNX3 expression made cancer cells sensitive to TGF- $\beta$-induced apoptosis [21,35-38]. These reports suggest that TGF- $\beta$ is required for RUNX3related apoptosis. In the present study, ectopic RUNX3 expression enhanced serum starvation-induced apoptosis in the absence of TGF- $\beta$. This discrepancy may be explained by the autocrine action of TGF- $\beta$ in Hep3B cells, which have an intact TGF- $\beta$ signaling pathway [39]. Furthermore, some HCC cell lines, including Hep3B, produce TGF- $\beta$ [40]. Further study is required to establish whether TGF- $\beta$ is involved in the enhanced apoptosis of HCC.

It has been reported that $\mathrm{p} 53, \mathrm{Rb}, \mathrm{p} 16$, phosphatase, and tensin homolog (PTEN) are altered in HCC. The p53 gene is the most extensively studied gene of solid tumors. Alteration of this gene occurs at a relative low frequency $(28-42 \%)$ in HCC compared to other solid tumors $[11,17,41,42]$. The Rb gene is another well-studied tumor suppressor gene in HCC and other solid tumors. $\mathrm{Rb}$ mutations are found in only $15 \%$ of HCCs [42]. The $\mathrm{LOH}$ of chromosome $13 \mathrm{q}$, where $\mathrm{Rb}$ gene is located, is more frequent in HCC (25-48\%) [43,44]. The p16 gene, also known as the cyclin-dependent kinase inhibitor $2 \mathrm{~A}$ gene, regulates the $\mathrm{Rb}$ pathway and is found in $64 \%$ of HCCs [9]. PTEN negatively regulates the PI3K/Akt signaling pathway, which is involved in the regulation of cell survival [45]. Alteration of PTEN was found in $\sim 40 \%$ of HCCs [10]. The frequency of alteration of each individual gene was relatively low, while RUNX3 expression was frequently down-regulated in both human HCC cell lines (91\%) and tissues (90\%).

Alterations in some tumor suppressor genes are due to $\mathrm{LOH}$ in HCC [17]. Similar to other tumor suppressor genes, some of the alterations in RUNX3 are due to the LOH of chromosome 1p36, where RUNX3 is located. Perhaps another mechanism for RUNX3 down-regulation is hypermethylation of the RUNX3 promoter region [13-16]. In a previous report, $30-40 \%$ of HCCs showed LOH of the RUNX3 gene and 40-80\% showed promoter hypermethylation [28]. In agreement with these reports, RUNX3 down-regulation was detected in $~ 90 \%$ of HCC tissue specimens.

\section{Conclusions}

RUNX3 expression elicits serum starvation-induced apoptosis in HCC cells via the Bim-caspase pathway. Because RUNX3 expression is generally suppressed in HCC cell lines and tissues, loss of RUNX3 expression leads to tumorigenesis by escaping apoptosis.

\section{Acknowledgements}

We thank Tatsuya Fujikawa and Naoki Ueda for their valuable suggestions, and Noriaki Tanaka for providing the HCC tissues.

\section{Author details}

${ }^{1}$ Department of Gastroenterology and Hepatology, Okayama University Graduate School of Medicine and Dentistry, 2-5-1 Shikata-cho, Okayama 7008558, Japan. ${ }^{2}$ Department of Molecular Hepatology, Okayama University Graduate School of Medicine and Dentistry, 2-5-1 Shikata-cho, Okayama 7008558, Japan. ${ }^{3}$ Department of Gastroenterological Surgery, Transplant, and Surgical Oncology, Okayama University Graduate School of Medicine and Dentistry, 2-5-1 Shikata-cho, Okayama 700-8558, Japan. 


\section{Authors' contributions}

HS conceived the design and drafted the manuscript. YN performed experiments. NT, ST, SN, MU, MM, MI and AT helped performing experiments for YN. SN, YK, KN, KK, HH, JT, HO and TY contributed for the collection of HCC tissues. YN performed immunohistochemical study. KY provides financial supports and participates in the discussion of the results. Al authors read and approved the final manusctipt.

\section{Competing interests}

The authors declare that they have no competing interests.

Received: 10 August 2010 Accepted: 4 January 2011

Published: 4 January 2011

\section{References}

1. El-Serag HB, Rudolph KL: Hepatocellular carcinoma: epidemiology and molecular carcinogenesis. Gastroenterology 2007, 132(7):2557-2576.

2. Garcia M, Jernal A, Ward EM, M CM, Hao Y, Siegel RI, Thun MJ: Global Cancer Facts \& Figures 2007. Society AC. Atlanta, GA; 2007.

3. Parkin DM, Bray F, Ferlay J, Pisani P: Estimating the world cancer burden: Globocan 2000. Int J Cancer 2001, 94(2):153-156.

4. El-Serag HB, Mason AC: Rising incidence of hepatocellular carcinoma in the United States. N Engl J Med 1999, 340(10):745-750

5. Kremer-Tal S, Reeves HL, Narla G, Thung SN, Schwartz M, Difeo A, Katz A, Bruix J, Bioulac-Sage P, Martignetti JA, et al: Frequent inactivation of the tumor suppressor Kruppel-like factor 6 (KLF6) in hepatocellular carcinoma. Hepatology 2004, 40(5):1047-1052.

6. Kaposi-Novak P, Lee JS, Gomez-Ouiroz L, Coulouarn C, Factor VM, Thorgeirsson SS: Met-regulated expression signature defines a subset of human hepatocellular carcinomas with poor prognosis and aggressive phenotype. The Journal of clinical investigation 2006, 116(6):1582-1595.

7. Shachaf CM, Kopelman AM, Arvanitis C, Karlsson A, Beer S, Mandl S, Bachmann MH, Borowsky AD, Ruebner B, Cardiff RD, et al: MYC inactivation uncovers pluripotent differentiation and tumour dormancy in hepatocellular cancer. Nature 2004, 431(7012):1112-1117.

8. Sicklick JK, Li YX, Melhem A, Schmelzer E, Zdanowicz M, Huang J, Caballero M, Fair JH, Ludlow JW, McClelland RE, et al: Hedgehog signaling maintains resident hepatic progenitors throughout life. American journal of physiology 2006, 290(5):G859-870.

9. Azechi H, Nishida N, Fukuda Y, Nishimura T, Minata M, Katsuma H, Kuno M, Ito T, Komeda T, Kita R, et al: Disruption of the p16/cyclin D1/ retinoblastoma protein pathway in the majority of human hepatocellular carcinomas. Oncology 2001, 60(4):346-354

10. Hu TH, Huang CC, Lin PR, Chang HW, Ger LP, Lin YW, Changchien CS, Lee $\mathrm{CM}$, Tai MH: Expression and prognostic role of tumor suppressor gene PTEN/MMAC1/TEP1 in hepatocellular carcinoma. Cancer 2003, 97(8):1929-1940

11. Tannapfel A, Busse C, Weinans L, Benicke M, Katalinic A, Geissler F, Hauss J, Wittekind C: INK4a-ARF alterations and p53 mutations in hepatocellular carcinomas. Oncogene 2001, 20(48):7104-7109.

12. Yamada T, De Souza AT, Finkelstein S, Jirtle RL: Loss of the gene encoding mannose 6-phosphate/insulin-like growth factor II receptor is an early event in liver carcinogenesis. Proc Natl Acad Sci USA 1997 94(19):10351-10355.

13. Fujimoto $Y$, Hampton $L L$, Wirth PJ, Wang $N$, Xie JP. Thorgeirsson SS: Alterations of tumor suppressor genes and allelic losses in human hepatocellular carcinomas in China. Cancer Res 1994, 54(1):281-285.

14. Kawai H, Suda T, Aoyagi Y, Isokawa O, Mita Y, Waguri N, Kuroiwa T, Igarashi M, Tsukada K, Mori S, et al: Quantitative evaluation of genomic instability as a possible predictor for development of hepatocellular carcinoma: comparison of loss of heterozygosity and replication error. Hepatology 2000, 31(6):1246-1250

15. Nishida N, Nagasaka T, Nishimura T, Ikai I, Boland CR, Goel A: Aberrant methylation of multiple tumor suppressor genes in aging liver, chronic hepatitis, and hepatocellular carcinoma. Hepatology 2008, 47(3):908-918.

16. Yang B, Guo M, Herman JG, Clark DP: Aberrant promoter methylation profiles of tumor suppressor genes in hepatocellular carcinoma. Am $J$ Pathol 2003, 163(3):1101-1107.

17. Buendia MA: Genetics of hepatocellular carcinoma. Semin Cancer Biol 2000, 10(3):185-200.
18. Ito K, Liu Q, Salto-Tellez M, Yano T, Tada K, Ida H, Huang C, Shah N, Inoue M, Rajnakova A, et al: RUNX3, a novel tumor suppressor, is frequently inactivated in gastric cancer by protein mislocalization. Cancer Res 2005, 65(17):7743-7750.

19. Ito $Y$, Miyazono K: RUNX transcription factors as key targets of TGF-beta superfamily signaling. Curr Opin Genet Dev 2003, 13(1):43-47.

20. Hanai J, Chen LF, Kanno T, Ohtani-Fujita N, Kim WY Guo WH, Imamura T, Ishidou Y, Fukuchi M, Shi MJ, et al: Interaction and functional cooperation of PEBP2/CBF with Smads. Synergistic induction of the immunoglobulin germline Calpha promoter. J Biol Chem 1999, 274(44):31577-31582.

21. Li QL, Ito K, Sakakura C, Fukamachi H, Inoue K, Chi XZ, Lee KY, Nomura S, Lee CW, Han SB, et al: Causal relationship between the loss of RUNX3 expression and gastric cancer. Cell 2002, 109(1):113-124.

22. Yamamura $Y$, Lee $W L$, Inoue $K$, Ida $H$, Ito $Y$ : RUNX3 cooperates with FoxO3a to induce apoptosis in gastric cancer cells. J Biol Chem 2006, 281(8):5267-5276.

23. Araki K, Osaki M, Nagahama Y, Hiramatsu T, Nakamura H, Ohgi S, Ito H: Expression of RUNX3 protein in human lung adenocarcinoma: Implications for tumor progression and prognosis. Cancer Sci 2005, 96(4):227-231.

24. Ku JL, Kang SB, Shin YK, Kang HC, Hong SH, Kim IJ, Shin JH, Han IO, Park JG: Promoter hypermethylation downregulates RUNX3 gene expression in colorectal cancer cell lines. Oncogene 2004, 23(40):6736-6742.

25. Li J, Kleeff J, Guweidhi A, Esposito I, Berberat PO, Giese T, Buchler MW, Friess H: RUNX3 expression in primary and metastatic pancreatic cancer. J Clin Pathol 2004, 57(3):294-299.

26. Wada M, Yazumi S, Takaishi S, Hasegawa K, Sawada M, Tanaka H, Ida H, Sakakura $C$, Ito $K$, Ito $Y$, et al: Frequent loss of RUNX3 gene expression in human bile duct and pancreatic cancer cell lines. Oncogene 2004, 23(13):2401-2407.

27. Mori T, Nomoto S, Koshikawa K, Fujii T, Sakai M, Nishikawa Y, Inoue S, Takeda S, Kaneko T, Nakao A: Decreased expression and frequent allelic inactivation of the RUNX3 gene at 1p36 in human hepatocellular carcinoma. Liver Int 2005, 25(2):380-388

28. Xiao WH, Liu WW: Hemizygous deletion and hypermethylation of RUNX3 gene in hepatocellular carcinoma. World I Gastroenterol 2004, 10(3):376-380.

29. Li X, Zhang Y, Qiao T, Wu K, Ding J, Liu J, Fan D: RUNX3 Inhibits Growth of HCC Cells and HCC Xenografts in Mice in Combination With Adriamycin. Cancer Biol Ther 2008, 7(5)

30. Ng IO, Chung LP, Tsang SW, Lam CL, Lai EC, Fan ST, Ng M: p53 gene mutation spectrum in hepatocellular carcinomas in Hong Kong Chinese. Oncogene 1994, 9(3):985-990.

31. Yano T, Ito K, Fukamachi H, Chi XZ, Wee HJ, Inoue K, Ida H, Bouillet P Strasser A, Bae SC, et al: The RUNX3 tumor suppressor upregulates Bim in gastric epithelial cells undergoing transforming growth factor betainduced apoptosis. Mol Cell Biol 2006, 26(12):4474-4488.

32. O'Connor L, Strasser A, O'Reilly LA, Hausmann G, Adams JM, Cory S, Huang DC: Bim: a novel member of the BCl-2 family that promotes apoptosis. Embo J 1998, 17(2):384-395.

33. Puthalakath H, Huang DC, O'Reilly LA, King SM, Strasser A: The proapoptotic activity of the $\mathrm{BCl}-2$ family member Bim is regulated by interaction with the dynein motor complex. Molecular cell 1999 3(3):287-296.

34. Brunet $\mathrm{A}$, Bonni A, Zigmond MJ, Lin MZ, Juo P, Hu LS, Anderson MJ, Arden KC, Blenis J, Greenberg ME: Akt promotes cell survival by phosphorylating and inhibiting a Forkhead transcription factor. Cell 1999, 96(6):857-868

35. Guo C, Ding J, Yao L, Sun L, Lin T, Song Y, Fan D: Tumor suppressor gene Runx3 sensitizes gastric cancer cells to chemotherapeutic drugs by downregulating BCl-2, MDR-1 and MRP-1. Int I Cancer 2005.

36. Osaki M, Moriyama M, Adachi K, Nakada C, Takeda A, Inoue Y, Adachi H, Sato $\mathrm{K}$, Oshimura $\mathrm{M}$, Ito H: Expression of RUNX3 protein in human gastric mucosa, intestinal metaplasia and carcinoma. Eur J Clin Invest 2004, 34(9):605-612.

37. Torquati A, O'Rear L, Longobardi L, Spagnoli A, Richards WO, Daniel Beauchamp R: RUNX3 inhibits cell proliferation and induces apoptosis by reinstating transforming growth factor beta responsiveness in esophageal adenocarcinoma cells. Surgery 2004, 136(2):310-316.

38. Jin YH, Jeon EJ, Li QL, Lee YH, Choi JK, Kim WJ, Lee KY, Bae SC: Transforming growth factor-beta stimulates p300-dependent RUNX3 
acetylation, which inhibits ubiquitination-mediated degradation. $J$ Biol Chem 2004, 279(28):29409-29417.

39. Li G, Wang S, Gelehrter TD: Identification of glucocorticoid receptor domains involved in transrepression of transforming growth factor-beta action. J Biol Chem 2003, 278(43):41779-41788.

40. Mouri H, Sakaguchi K, Sawayama T, Senoh T, Ohta T, Nishimura M, Fujiwara A, Terao M, Shiratori Y, Tsuji T: Suppressive effects of transforming growth factor-beta1 produced by hepatocellular carcinoma cell lines on interferon-gamma production by peripheral blood mononuclear cells. Acta Med Okayama 2002, 56(6):309-315.

41. Bressac B, Kew M, Wands J, Ozturk M: Selective G to T mutations of $\mathrm{p} 53$ gene in hepatocellular carcinoma from southern Africa. Nature 1991, 350(6317):429-431.

42. Ozturk M: Genetic aspects of hepatocellular carcinogenesis. Semin Liver Dis 1999, 19(3):235-242.

43. Higashitsuji $\mathrm{H}$, Itoh K, Nagao T, Dawson S, Nonoguchi K, Kido T, Mayer RJ, Arii S, Fujita J: Reduced stability of retinoblastoma protein by gankyrin, an oncogenic ankyrin-repeat protein overexpressed in hepatomas. Nature medicine 2000, 6(1):96-99.

44. Hsia CC, Di Bisceglie AM, Kleiner DE Jr, Farshid M, Tabor E: RB tumor suppressor gene expression in hepatocellular carcinomas from patients infected with the hepatitis B virus. Journal of medical virology 1994, 44(1):67-73.

45. Li DM, SUn H: PTEN/MMAC1/TEP1 suppresses the tumorigenicity and induces G1 cell cycle arrest in human glioblastoma cells. Proc Natl Acad Sci USA 1998, 95(26):15406-15411.

\section{Pre-publication history}

The pre-publication history for this paper can be accessed here: http://www.biomedcentral.com/1471-2407/11/3/prepub

doi:10.1186/1471-2407-11-3

Cite this article as: Nakanishi et al.: Loss of runt-related transcription factor 3 expression leads hepatocellular carcinoma cells to escape apoptosis. BMC Cancer 2011 11:3.

\section{Submit your next manuscript to BioMed Central} and take full advantage of:

- Convenient online submission

- Thorough peer review

- No space constraints or color figure charges

- Immediate publication on acceptance

- Inclusion in PubMed, CAS, Scopus and Google Scholar

- Research which is freely available for redistribution

Submit your manuscript at www.biomedcentral.com/submit
Biomed Central 